\title{
Three Cases of Gradual Degradation Mode Analysis of Semiconductor Laser Diodes
}

\author{
Jack Jia-Sheng Huang ${ }^{1,2}$, C. K. Wang ${ }^{2} \&$ Yu-Heng Jan ${ }^{1,2}$ \\ ${ }^{1}$ Source Photonics, 8521 Fallbrook Avenue, Suite 200, West Hills, CA 91304, USA \\ ${ }^{2}$ Source Photonics, No.46, Park Avenue $2^{\text {nd }}$ Rd., Science Park, Hsinchu, Taiwan \\ Correspondence: Jack Jia-Sheng Huang, Source Photonics, 8521 Fallbrook Avenue, Suite 200, West Hills, CA \\ 91304, USA \& Source Photonics, No.46, Park Avenue $2^{\text {nd }}$ Rd., Science Park, Hsinchu, Taiwan.
}

Received: September 14, 2021

Accepted: October 22, 2021

Online Published: October 26, 2021

doi:10.5539/mas.v15n6p27

URL: https://doi.org/10.5539/mas.v15n6p27

\begin{abstract}
Semiconductor laser diodes are important components for various applications such as $5 \mathrm{G}$ wireless, datacenter, passive optical network, and aerospace applications. High reliability has emerged to be the universal requirement for all optical applications. To achieve high reliability, fundamental understanding of the laser degradation behavior is crucial. In this paper, we study three cases of gradual degradataion modes of laser diodes including (1) Pattern-A that is associated with threshold current change only, (2) Pattern-B that involve both threshold current and power changes, and (3) Pattern-C that is associated with merely power change. We have instituted reliability equations for the degradation processes. The new reliability models could provide estimation on the laser end-of-life based on the degradation rate and device performance specification.
\end{abstract}

Keywords: laser degradation, laser diode, gradual degradation, 5G wireless, mobile network, datacenter, aerospace

\section{Introduction}

\subsection{General Reliability Requirement of Optical Components}

Optical components are critical building blocks for various fiber optic systems. For modern optical networks, high reliability and excellent performance have become equally important (Nelson, 2017; Huang et al., 2017; Ichikawa et al., 2010; Hogan, 2019; Paoletti et al., 2009). For the latter, device performance strongly depends on the requirements of the applications and customers. For reliability, it is universally important across all sectors of the optical applications. Traditionally, high reliability was mainly focused on areas of expensive or hardly accessible equipment such as undersea fiber networks, aerospace, and satellite laser terminals (Häusler et al., 2008; Sawruk, 2020; Huang et al., 2016). Nowadays, high-volume components such as fifth-generation (5G) wireless and datacom lasers also require high reliability performance (Keith, 2019; Rambo, 2019; Huang et al., 2017).

\subsection{Issues of Laser Reliability}

Reliability is ultimately the principal denominator to determine the success of the optical modules and transceivers. Because of the high reliability requirement, component suppliers need to guarantee the chip reliability to the ever increasingly stringent level. One of the most challenging reliability issues is to assure continuous uptime operation for harsh environment. Among the optical components, the laser diode perhaps presents the most challenges since the laser light source needs to sustain electrical, optical, and thermal stresses.

\subsection{Objective of Laser Reliability Design}

The laser component represents significant portion of the overall optical module cost. It is crucial to include reliability considerations at the early development stage of laser design. Although reliability studies have been widely conducted in industry and academia, very few focused on the aspect of design-in reliability (Huang, 2011; Huang, 2012; Mohamed et al., 2014). The previous work of design reliability was limited to generic description or specific device. However, universal reliability models applicable for a broad range of laser components are lacking. 
In this paper, we present universal reliability models that can describe the degradation behaviors of various laser devices. We report three categories of degradation behaviors of gradual wear-out laser degradation. With the new modeling of the laser degradation behaviors, we can more effectively incorporate robust reliability in our laser design. The analytical models of degradation Pattern A, B and C can also help assess the device performance and reliability margin for end-of-life.

\section{Method}

\subsection{Semiconductor Laser Device Fabrication}

Figures 1 (a) and (b) show the schematics of the buried heterostructure (BH) and ridge waveguide (RWG) laser structures (Huang et al., 2018; Huang, 2015). The n-type InP, multi-quantum well (MQW), and p-type InP were grown sequentially by metal organic chemical vapor deposition (MOCVD). The MQW materials were InGaAsP and InGaAlAs for the BH and RWG, respectively. The distributed feedback (DFB) single-mode lasing was defined by holographic grating. The contact layer was formed with the heavily-doped $\mathrm{p}^{+}-\mathrm{InGaAs}$ for both $\mathrm{BH}$ and RWG. The wafer was cleaved into laser bars; the bars were deposited with optical coatings to optimize performance and reliability (Huang et al., 2018).

(a)

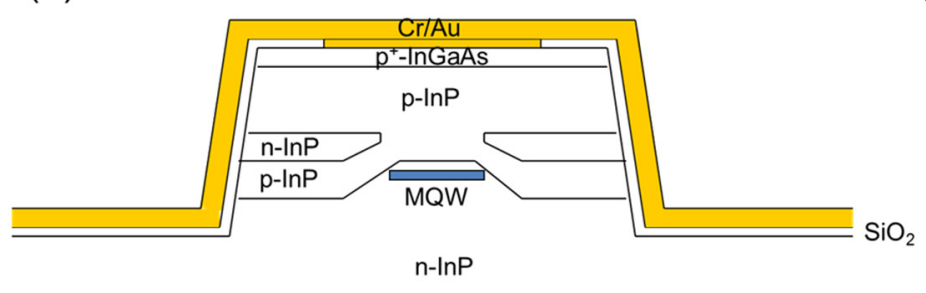

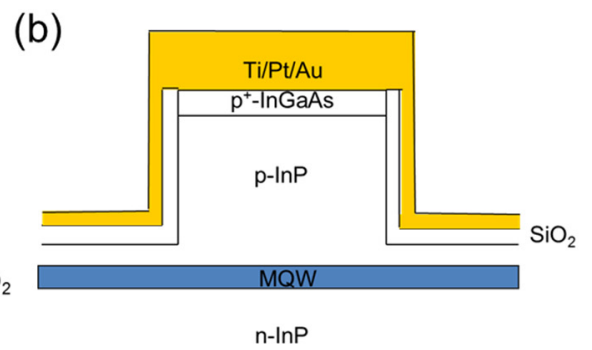

Figure 1. Schematics of (a) buried heterostructure and (b) ridge waveguide lasers

\subsection{Laser Reliability Stresses}

The laser chips were stressed by highly accelerated life test (ALT) under constant current and constant temperature (Huang, 2005; Huang, 2006). For long-cavity BH laser with a cavity length of $1000 \mathrm{~mm}$, the ALT condition was $100^{\circ} \mathrm{C}, 500 \mathrm{~mA}$. For short-cavity RWG laser $(150 \mathrm{~mm} \mathrm{long})$, the ALT condition was $110^{\circ} \mathrm{C}, 85$ $\mathrm{mA}$. Room temperature $\left(25^{\circ} \mathrm{C}\right)$ light vs. current (LI) curves were taken at every 100 -hour interval during ALT. Threshold current $\left(\mathrm{I}_{\mathrm{th}}\right)$ was derived from the LI curve. Above the $\mathrm{I}_{\mathrm{th}}$, the output power increased with the bias current due to stimulated emission.

\section{Results}

\subsection{Degradation Pattern A}

The BH lasers typically exhibit more pronounced change in the threshold current compared to the RWG (Huang et al., 2017; Huang, 2015). The first type of BH laser degradation is classified as Pattern A where the laser exhibits a change in the threshold current, but little or no change in the slope efficiency. Figures 2 (a) and (b) show the LI change and slope efficiency (SE) change before and after 500-hour life test, respectively. The $\mathrm{BH}$ laser with a cavity length of $1000 \mathrm{~mm}$ was subjected to ALT condition of $100^{\circ} \mathrm{C}, 500 \mathrm{~mA}$. The degradation of Pattern A was typically related to the regrowth interface, which was more pronounced in the BH laser (Fukuda et al., 1985; Fukuda et al., 1994). 
(a)

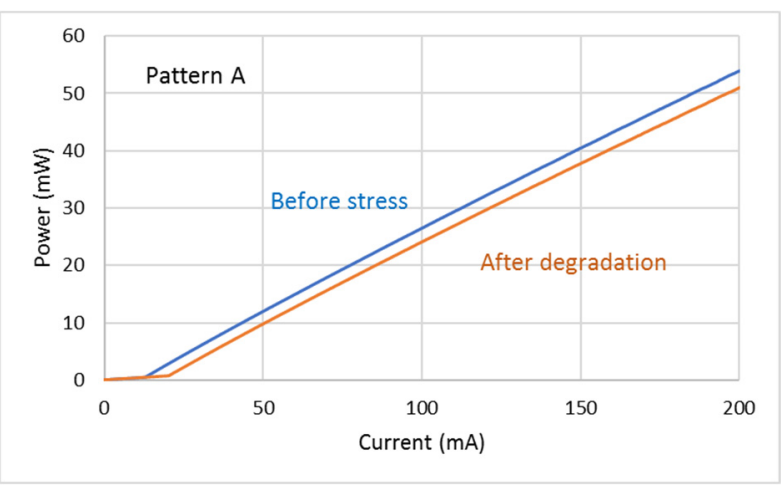

(b)

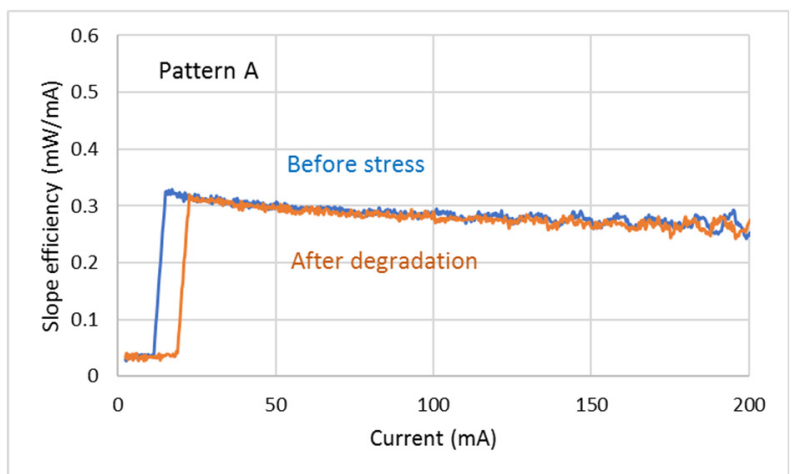

Figure 2. Pattern A degradation taken from the BH laser. (a) LI change and (b) SE change before and after 500-hour ALT stress (after Huang, 2015)

\subsection{Degradation Pattern $B$}

The second type of BH laser degradation is Pattern B, featured with changes in both threshold current and slope efficiency (Huang, 2015). This is arguably the most common failure mode of BH laser degradation. Figure 3(a) shows the LI curves before and after degradation of a BH laser (1000 $\mathrm{mm}$ long). The threshold current increases, and the output power decreases after 500 hours of ALT at the stress condition of $100^{\circ} \mathrm{C}, 500 \mathrm{~mA}$. Figure $3(\mathrm{~b})$ shows the slope efficiency curves before and after degradation. The degradation of Pattern B was typically related to the active region and the regrowth interface when the BH laser was subjected to very severe stress conditions.

(a)

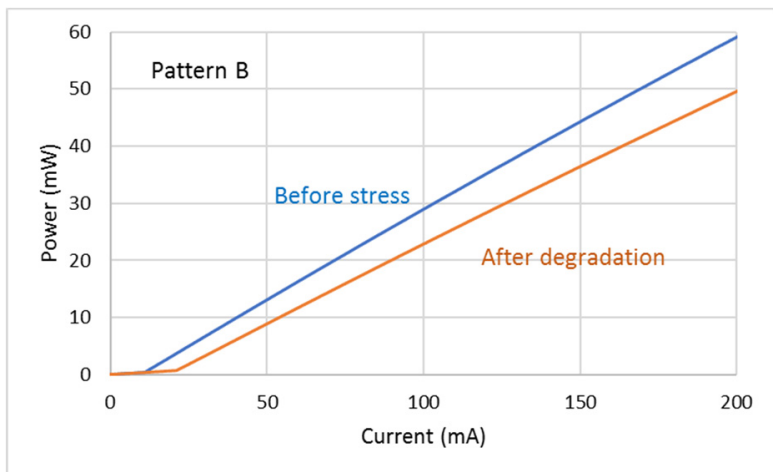

(b)

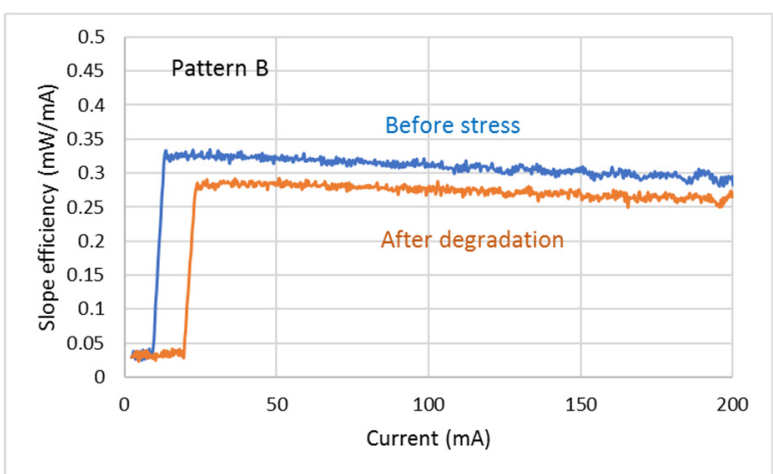

Figure 3. Pattern B degradation taken from the BH laser. (a) LI change and (b) SE change before and after 500-hour ALT stress (after Huang, 2015)

\subsection{Degradation Pattern C}

For short-cavity RWG laser, Pattern C degradation is sometimes observed. The Pattern C degradation exhibits only a decrease in the slope efficiency, but essentially no change in the threshold current. This type of failure mode is sometimes referred as "freak failure" (Häusler et al., 2008). A dark line loop along the laser stripe may be responsible the freak failure. Figures 4 (a) and (b) show the LI and SE changes taken from a short-cavity RWG laser before and after 500-hour ALT, respectively. The RWG laser with a cavity length of $150 \mathrm{~mm}$ was subjected to ALT condition of $110^{\circ} \mathrm{C}, 85 \mathrm{~mA}$. 
(a)

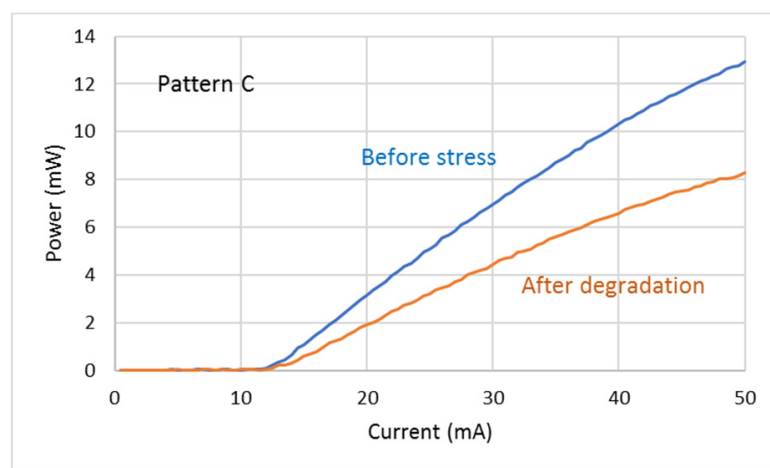

(b)

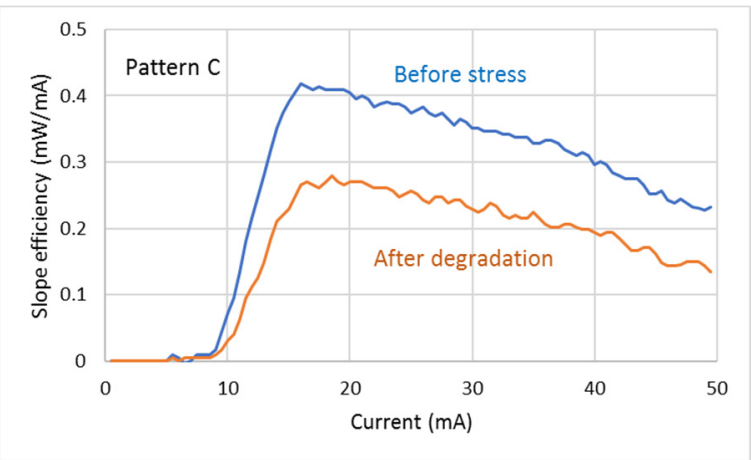

Figure 4. Pattern C degradation taken from the RWG laser. (a) LI change and (b) SE change before and after 500-hour ALT stress

\section{Discussion}

To further quantify the three degradation modes in the laser design, we institute the analytical model for each degradation pattern. The reliability model could assist laser engineers in including the reliability aspects during the design phase. The formulas can provide good estimation on the laser end-of-life based on the degradation rate and device performance specification.

\subsection{Reliability Model of Degradation Pattern A}

Here we attempt to formulate the change of threshold current for degradation Pattern A. Assuming that the change of threshold current is determined by recombination enhanced defect generation (REDG) process (Häusler et al., 2008; Jiménez, 2003; Hempel et al., 2013; Tomm et al., 2011), the rate of defect generation is proportional to the non-radiative current, depicted by Equation (1). The Chuang and Lam models are based on exponential functions that can provide good description of the early stage of degradation (Chuang et al., 1998; Lam et al., 2003).

$$
\Delta \mathrm{I}_{\text {th }}=\mathrm{I}_{\text {nro }}\left\{\exp \left[\mathrm{K}_{\text {tho }} \exp \left(-\mathrm{E}_{\mathrm{a}} / \mathrm{kT}\right) \cdot \mathrm{t}\right]-1\right\}
$$

Where $\Delta \mathrm{I}_{\mathrm{th}}$ is the change of threshold current, $\mathrm{I}_{\text {nro }}$ is the non-radiative current, $\mathrm{K}_{\text {tho }}$ is the prefactor, $\mathrm{E}_{\mathrm{a}}$ is the activation energy for degradation pattern $\mathrm{A}, \mathrm{k}$ is Boltzmann's constant, $\mathrm{T}$ is temperature, and $\mathrm{t}$ is aging time.

\subsection{Reliability Model of Degradation Pattern B}

The change of threshold current for Pattern B can be expressed by exponential function as shown in Equation (2) where $I_{n r 1}$ is the non-radiative current, $K_{t h 1}$ is the prefactor, and $E_{a 1}$ is the activation energy for degradation pattern B.

$$
\Delta \mathrm{I}_{\mathrm{th}}=\mathrm{I}_{\mathrm{nr} 1}\left\{\exp \left[\mathrm{K}_{\mathrm{th} 1} \exp \left(-\mathrm{E}_{\mathrm{a} 1} / \mathrm{kT}\right) \cdot \mathrm{t}\right]-1\right\}
$$

The change of output power can be formulated by exponential function in Equation (3).

$$
\Delta \mathrm{P}=\mathrm{P}_{\mathrm{o}}\{\exp (-\mathrm{t} / \tau)-1\}
$$

Where $\Delta \mathrm{P}$ is the change of output power, $\mathrm{P}_{\mathrm{o}}$ is the initial output power, $\mathrm{t}$ is the aging time, and $\tau$ is the time constant for power decay (Ott, 1997).

\subsection{Reliability Model of Degradation Pattern C}

The change of output power for Pattern $\mathrm{C}$ can be formulated by exponential function in Equation (4).

$$
\Delta \mathrm{P}=\mathrm{P}_{\mathrm{o}}\left\{\exp \left(-\mathrm{t} / \tau_{1}\right)-1\right\}
$$

where $\Delta \mathrm{P}$ is the change of output power, $\mathrm{P}_{\mathrm{o}}$ is the initial output power, $\mathrm{t}$ is the aging time, and $\tau_{1}$ is the time constant for power decay.

\section{Conclusion}

We have studied the gradual degradation characteristics of BH and RWG lasers. For Pattern-A mode, the laser degradation is manifested by the increase in threshold current that is attributed to the degradation process at the $\mathrm{BH}$ regrowth interface. For Pattern-B, the degradation involves both threshold current and slope efficiency changes. The Pattern B degradation is typically related to the active region and the regrowth interface. For 
Pattern-C, the degradation is shown by the decrease in output power or slope efficiency. Such degradation typically occurs at the short-cavity RWG laser where the stress current density is very high.

To further quantify the three degradation modes, we have instituted the analytical model for each degradation pattern. The reliability model could assist laser engineers in the reliability design-in during the product development phase. The formulas can provide preliminary estimation on the laser end-of-life based on the degradation rate and device performance specification. To achieve more accurate end-of-life estimation, future research is needed to determine the coefficient in the reliability model.

\section{Acknowledgment}

The authors would like to thank Sam Hsiang, Ansel Chen and Dawei Ren (Source Photonics, Taiwan) for MOCVD growth, NiYeh Wu and S. C. Huang (Source Photonics, Taiwan) for mask design and wafer processing, Emin Chou (Source Photonics, Taiwan) for support of this work, and Shannon Huang (UCLA, USA) for proofreading.

\section{References}

Chuang, S. L., Nakayama, N., Ishibashi, A., Taniguchi, S., \& Nakano, K. (1998). Degradation of II-VI blue-green semiconductor lasers. IEEE Journal of Quantum Electronics, 34(5), 851-857. https://doi.org/10.1109/3.668773

Fukuda, M., \& Iwane, G. (1985). Degradation of active region in InGaAsP/InP buried heterostructure lasers. Journal of Applied Physics, 58(8), 2932. https://doi.org/10.1063/1.336298

Fukuda, M., Okayasu, M., Temmyo, J., \& Nakand, J. (1994). Degradation behavior of $0.98 \mu \mathrm{m}$ strained quantum well InGaAs/AlGaAs lasers under high-power operation. IEEE Journal of Quantum Electronics, 30(2), 471-476. https://doi.org/10.1109/3.283796

Häusler, K., Zeimer, U., Sumpf, B., Erbert, G., \& Tränkle, G. (2008). Degradation model analysis of laser diodes. Journal of Materials Science: Materials in Electronics, 19, 160-164. https://doi.org/10.1007/s10854-007-9534-8

Hempel, M., Tomm, J. W., Mattina, F. L., Ratschinski, I., Schade, M., Shorubalko, I., Stiefel, M., Leipner, H. S., Kießling, F. M., \& Elsaesser, T. (2013). Microscopic Origins of Catastrophic Optical Damage in Diode Lasers. IEEE Journal of Selected Topics in Quantum Electronics, 19(4). https://doi.org/10.1109/JSTQE.2012.2236303

Hogan, H. (2019). Data Centers and More for Silicon Photonics. Photonics Spectra (August).

Huang, J. S. (2005). Temperature and current dependences of reliability degradation of buried heterostructure semiconductor lasers. IEEE Transactions on Device and Materials Reliability, 5(1), 150-154. https://doi.org/10.1109/TDMR.2005.843834

Huang, J. S. (2006). Reliability extrapolation methodology of semiconductor laser diodes: is a quick life test feasible? IEEE Transactions on Device and Materials Reliability, 6(1), 46-51. https://doi.org/10.1109/TDMR.2006.870346

Huang, J. S. (2011). Design-in reliability of modern distributed feedback (DFB) InP lasers: Can we meet up the stringent wavelength-division multiplex (WDM) requirement? 2011 IEEE Photonics Society Summer Topical Meeting Series, 2011, pp. 89-90. https://doi.org/10.1109/PHOSST.2011.6000059

Huang, J. S. (2012). Design-in reliability for modern wavelength-division multiplex (WDM) distributed feedback (DFB) InP lasers. Applied Physics Research, 4(2), 15-28. https://doi.org/10.5539/apr.v4n2p15

Huang, J. S. (2015). Reliability of Optoelectronics. In Jonathan Swingler (Ed.), Reliability Characterisation of Electrical and Electronic Systems (pp. 83-114). https://doi.org/10.1016/B978-1-78242-221-1.00006-X

Huang, J. S., \& Jan, Y. H. (2017). Environmental engineering of photonic and electronic reliabilities: from technology and energy efficiency perspectives. Edited Marco Braga (Scholars' Press, Saarbrücken, Germany).

Huang, J. S., Jan, Y. H., Chang, H. S., Chang, J., Chang, R., Liu, G., Ren, D., \& Chou, E. (2017). ESD polarity effect study of monolithic, integrated DFB-EAM EML for 100/400G optical networks. In 2017 Conference on Lasers and Electro-Optics Pacific Rim (CLEO-PR) (Singapore, July 31-Aug. 4), Paper\#S1018. https://doi.org/10.1109/CLEOPR.2017.8118609 
Huang, J. S., Jan, Y. H., Chang, J., Hsu, Y., Ren, D., \& Chou, E. (2016). Swift reliability test methodology of 100G high-speed, energy-efficient electro-absorption modulated lasers (EML) for green datacenter networks. Studies in Engineering \& Technology, 3(1), 74-80. https://doi.org/10.11114/set.v3i1.1727

Huang, J. S., Jan, Y. H., Chang, R., Shiu, G., \& Chou, E. (2018). Front-rear LI linearity correlation of InGaAlAs uncooled $\left(-40^{\circ} \mathrm{C}\right.$ to $\left.+90^{\circ} \mathrm{C}\right)$ DML for robust tracking error in $10 \mathrm{G}$ E-PON ONU. In CLEO Pacific Rim Conference 2018, OSA Technical Digest (Optical Society of America, 2018), paper W4J.4. https://doi.org/10.1364/CLEOPR.2018.W4J.4

Huang, J. S., Jan, Y. H., Yu, D., Chang, R., Chang, J., Shiu, G., Ren, D., Wang, K., \& Chou, E. (2018). Manufacturing excellence and future challenges of wireless laser components for $4 \mathrm{G} / 5 \mathrm{G}$ optical mobile fronthaul networks. 2018 27th Wireless and Optical Communication Conference (WOCC) (April 30-May 1, Taiwan). https://doi.org/10.1109/WOCC.2018.8372709

Ichikawa, H., Kumagai, A., Kono, N., Matsukawa, S., Fukuda, C., Iwai, K., \& Ikoma, N. (2010). Dependence of facet stress on reliability of AlGaInAs edge-emitting lasers. Journal of Applied Physics, 107(8), 083109. https://doi.org/10.1063/1.3361156

Jiménez, J. (2003). Laser diode reliability: crystal defects and degradation modes. Comptes Rendus Physique, 4(6), 663-673. https://doi.org/10.1016/S1631-0705(03)00097-5

Keith, R. (2019). $5 G$ network reliability explained. Retrieved from https://www.a10networks.com/blog/5g-network-reliability-explained/

Lam, S. K. K., Mallard, R. E., \& Cassidy, D. T. (2003). Analytical model for saturable aging in semiconductor lasers. Journal of Applied Physics, 94(3), 1803-1809. https://doi.org/10.1063/1.1589594

Mohamed, M., Li, Z., Chen, X., Shang, L., \& Mickelson, A. R. (2014). Reliability-Aware Design Flow for Silicon Photonics On-Chip Interconnect. IEEE Transactions on Very Large Scale Integration (VLSI) Systems, 22(8), 1763-1776. https://doi.org/10.1109/TVLSI.2013.2278383

Nelson, P. (2017). Reliability, not principally speed, will drive 5G. Retrieved from https://www.networkworld.com/article/3157041/reliability-not-principally-speed-will-drive-5g.html

Ott, M. (1997). Capabilities and reliability of LEDs and laser diodes. NASA memo.

Paoletti, T., Agresti, M., Bertone, D., Bruschi, C., Codato, S., Coriasso, C., Defranceschi, R., Dellacasa, P., Diloreto, M., Fang, R. Y., Gotta, P., Meneghini, G., Rigo, E., Riva, C., Roggero, G., Stano, A., \& Meliga, M. (2009). Uncooled $20 \mathrm{~Gb} / \mathrm{s}$ direct modulation of high yield, highly reliable $1300 \mathrm{~nm}$ InGaAlAs ridge DFB lasers. In Optical Fiber Communication Conference and National Fiber Optic Engineers Conference, OSA Technical Digest (CD) (Optical Society of America, 2009), paper OThT1. https://doi.org/10.1364/OFC.2009.OThT1

Rambo, S. (2019). The growing challenges of 5 G reliability. Semi. Engi. (Dec. 10).

Sawruk, N. (2020). Engineering Laser Systems for Aerospace and Defense Applications. In Applied Industrial Optics 2019, OSA Technical Digest (Optical Society of America, 2019), paper M3A.2. https://doi.org/10.1364/AIO.2019.M3A.2

Tomm, J. W., Ziegler, M., \& Elsaesser, M. H. T. (2011). Mechanisms and fast kinetics of the catastrophic optical damage (COD) in GaAs-based diode lasers. Laser \& Photonics Review, 5(3), 422-441. https://doi.org/10.1002/lpor.201000023

\section{Copyrights}

Copyright for this article is retained by the author(s), with first publication rights granted to the journal.

This is an open-access article distributed under the terms and conditions of the Creative Commons Attribution license (http://creativecommons.org/licenses/by/4.0/). 